Article

\title{
What Game Narrative Are We Talking About? An Ontological Mapping of the Foundational Canon of Interactive Narrative Forms
}

\author{
Hartmut Koenitz ${ }^{(D)}$ \\ Professorship Interactive Narrative Design, HKU University of the Arts Utrecht, Nieuwekade 1, \\ 3511 RV Utrecht, The Netherlands; Hartmut.koenitz@hku.nl
}

Received: 6 July 2018; Accepted: 14 September 2018; Published: 20 September 2018

\begin{abstract}
There have been misunderstandings regarding "narrative" in relation to games, in part due to the lack of a shared understanding of "narrative" and related terms. Instead, many contrasting perspectives exist, and this state of affairs is an impediment for current and future research. To address this challenge, this article moves beyond contrasting definitions, and based on a meta-analysis of foundational publications in game studies and related fields, introduces a two-dimensional mapping along the dimensions of media specificity and user agency. Media specificity describes to what extent medium affects narrative, and user agency concerns how much impact a user has on a narrative. This mapping is a way to visualize different ontological positions on "narrative" in the context of game narrative and other interactive narrative forms. This instrument can represent diverse positions simultaneously, and enables comparison between different perspectives, based on their distance from each other and alignment with the axes. A number of insights from the mapping are discussed that demonstrate the potential for this process as a basis for an improved discourse on the topic.
\end{abstract}

Keywords: game narrative; interactive digital narrative; mapping; ludology; narratology; ludonarrative; shared vocabulary

\section{Introduction}

A foundational issue with respect to the relationship between games and narrative is the lack of a shared understanding of "narrative", as well as related terms like "story", "storytelling", or "fiction". Indeed, Jesper Juul in Half Real assesses the term "narrative" as "practically meaningless":

[... ] the term narrative has such a wide range of contradictory meanings and associations for different people and in different theories that it is practically meaningless unless specified in great detail. (Juul 2005)

Juul proceeds to analyze several definitions from outside game studies to support his assessment. However, so far, little attention has been paid to the differences in the understanding between different researchers and practitioners within the space of game studies, game design, and related fields broadly concerned with the theory and design of interactive digital narratives (IDN) (e.g., artificial intelligence (AI) for interactive narrative, interactive documentaries, narrative-focused installation pieces, etc.).

In this paper, I will introduce a mapping of different positions in order to acknowledge and visualize these differences, with the aim of improving the academic and professional discourse around games and narrative. The mapping is based on a meta-analysis of the ontological status of the word field surrounding "narrative" in a range of academic publications concerned with video games and other interactive narrative forms during its foundational period (1997-2006). 


\section{The Story So Far}

A first analysis of "narrative" in a range of academic publications concerned with video games during the last two decades uncovers a variety of different meanings. These include "narrative" as a human expression extended by encounters with the interactive digital medium (Murray 1997), as the result of the engagement with a cybertextual machine (Aarseth 1997), as a means to provide context (Juul 2005), as an experiential quality during the experience of work (Pearce 2004; Salen and Zimmerman 2004; Calleja 2009; Calleja 2013), as an analytical framework to understand artefacts (Montfort 2005; Fernández-Vara 2014; Ensslin 2014), or as an analytical entity challenged by the interactive aspect of video games (Ryan 2006).

So far, I have strategically chosen to omit papers from the main phase of the narratology versus ludology debate (1999-2004), in order to show that the ontological problem this paper is concerned with is not restricted to the adversarial positions in the debate, but existed before and since.

Unfortunately, these examples represent some of the most accessible cases-publications in which the authors take great care to explicitly define their usage of the term. Implicit definitions of "narrative" and related terms are widespread in academic and professional discourse, as I have argued previously (Koenitz 2016; Koenitz 2018), and thus often neither the particular meaning of the term nor its categorical status are readily accessible. In other words, one scholar's "experience dimension" might be another scholar's "narrative", and one developer's "level design" might be an audience member's "narrative". In that sense, both exist and are interrelated-different definitions and implicit definitions. The latter requires an additional analytical effort to identify the specific definition used. The focus of this article is to address the former.

The realization that the ontological status of vocabulary has not been at the center of attention is surprising, especially if we consider the relative novelty of these areas of study, as well as their interdisciplinary nature. If-for the sake of this argument-we take Murray's Hamlet on the Holodeck from 1997 as a pioneering effort in the academic investigation of interactive narrative (while acknowledging earlier efforts ${ }^{1}$ ), and the first issue of the Game Studies journal with Aarseth's (Aarseth 2001), Juul's (Juul 2001), and Eskelinen's articles (Eskelinen 2001) as "year one" (Aarseth 2001) of modern game studies (again, while being mindful of earlier work, e.g., Huizinga 1938; Caillois 1961), then it follows that none of these scholars themselves have been originally trained in the novel fields of interactive narrative or video games. Indeed, Murray's Ph.D. is in English Literature, Aarseth's is in Comparative Literature; only Juul's is in Video Game Theory (although completed in 2003, two years after the inaugural issue of Game Studies). Yet, when scholars originate in different traditions, there is a danger of misunderstanding, as the respective terms and underlying categorical concepts are not automatically understood. This is especially problematic when, at first glance, the vocabulary appears to be identical, yet no attempt was made to establish a shared understanding of the word field around narrative. During the so-called "narratology versus ludology" debate, the seemingly obvious question- "what do you mean by narrative (and related terms)?" was hardly asked. Instead, the protagonists treat terms in the word field around "narrative" as transparent, then at best, they provide a definition to support their respective understanding and engage in a discourse, with the aim to prove their opponent wrong. This strategy is a scholarly dead end, and so far has not led to a satisfying conclusion to the debate. While the "hot" phase of this (in)famous debate might seem to have ended around 2005, infrequent contributions kept it alive (Calleja 2009; Ryan 2006; Simons 2007; Calleja 2013; Calleja 2015), while more recently an edited collection (Kapell 2015) discussed the topic, and Bogost's 2017 article "Video Games Are Better Without Stories" (Bogost 2017) re-iterated the original rejection of narrative in games. While it might be productive to engage with the original

1 e.g., Laurel's (Laurel 1986) and Buckles' Ph.D. theses (Buckles 1985), Laurel's 1991 book (Laurel 1991) and the work by the hypertext fiction community, e.g., (Bolter and Joyce 1987; Bolter 1991; Bernstein et al. 1992; Landow 1992; Joyce 1995). 
arguments once more, from the distance of nearly two decades, the purpose of this paper is instead to propose a change of perspective.

\subsection{A Change of Perspective}

I would like to consider the possibility that both sides might present valid arguments on the backdrop of their respective disciplinary tradition. An actual debate never took place (cf. Gonzala Frasca's contemporary insight (Frasca 2003)), as this would have meant first investigating the ontological status of terminology—for example, of Murray's "story" (e.g., in (Murray 2004)) in comparison to Aarseth's use (e.g., in (Aarseth 2004)) of the same word. This aspect has certainly not garnered the necessary attention during the debate (or since). Therefore, I would like to suggest that at least some aspects of the debate can be traced back to differences in the respective ontological understanding, as both specific meaning and categorization differ between scholars.

\subsection{Examples of Ontological Differences}

Markku Eskelinen criticizes Janet Murray' interpretation of Tetris (AcademySoft 1984) as a narrative, when Murray characterizes it as a "[ ... ] perfect enactment of the over tasked lives of Americans in the 1990s - of the constant bombardment of tasks that demand our attention and that we must somehow fit into our overcrowded schedules and clear off our desks in order to make room for the next onslaught" (Murray 1998). In Eskelinen's view, Murray's interpretation is inappropriate because it wrongly categorizes a game as something it is not. However, Murray's reading of Tetris as an allegory for the continuous onslaught of daily tasks in late-20th-century capitalism is not surprising for a literary scholar, and is certainly not "wrong" in an absolute sense. Conversely, this does not mean that Eskelinen's analysis of Tetris as a game with specific mechanics is "wrong" either. The difference between these two analyses are rather the different levels of abstraction on which they operate. Eskelinen's concern is with the concrete material of Tetris, and is thus less abstract, while Murray addresses the more abstract question of the game's meaning as cultural expression. It might be helpful to consider the difference as akin to signifier and signified-two different and equally valid perspectives on the same artefact. From this perspective, Murray's 2004 declaration that "all games are narratives" is also not "narrativism"- a colonial approach that misconstrues interactive experiences as narratives-as Espen Aarseth alleges, but rather an abstract allegorical understanding of games as hero stories.

Therefore, while it might be a convenient theoretical shortcut to simply reject differing scholarly perspectives originating in other disciplines, this is actually where the work should begin rather than end. This is the purpose of a meta-study, to investigate the ontological status, respective framework, and definition. What do Murray, Eskelinen, and other scholars want to address? What is their understanding of narrative? Where does it come from? How do their concepts compare to other authors? What can we learn from the comparison?

Once we start with this perspective, Eskelinen's attempt at a clear distinction between games and narratives, which is "If I throw a ball at you I don't expect you to drop it and wait until it starts telling stories" (Eskelinen 2001), reveals itself to be less clear-cut on several levels. First, there is no generally accepted definition of what "telling stories" actually entails. While it might indeed be difficult to identify a "teller" in Eskelinen's hypothetical example, some papers (e.g., (Stern 2008; Koenitz 2016)) have argued against the categorization of game narrative as "telling". To stay with this image- - the ball might not tell a story, but could still convey a narrative in a specific context. This is especially true if we consider narrative forms that operate without words. Second, there is also the possibility of imagining a game in which the ball drop is a trigger for the players to start telling stories. Lastly, Eskelinen's example itself can be construed as a micro-narrative, and in this sense, the ball game has actually created a story, the one Eskelinen tells us. Every single one of these analyses represents a different lens on the same fact, which reframes Eskelinen's foregrounding of one that excludes narrative as just that, a specific preference that should be clearly marked as such. 


\section{Mappings}

For the time being, a generally accepted definition of "narrative" (and related terms like "story" and "storytelling") seems elusive, and thus any hope of a simple solution on that end might be naive. At the same time, this does not mean that there is no chance for a comprehensive understanding. The key here is to move beyond the binary property of definitions (what is/is not a narrative) towards a relational approach: how can we describe the relationship between different definitions? On which dimensions do they differ? For this purpose, spatial mappings are promising. Provided that the respective dimensions of such a mapping are carefully chosen, they can offer novel insights into the relationship between different positions.

N. Katherine Hayles' call for a "media-specific analysis" of digital forms of narration (Hayles 2002), provides a first dimension for this process. While she made her argument originally to point out the neglect of the aspect of mediated representation in the humanities, this question also has a more universal application that fits the present topic. I call this dimension "media specificity". It investigates the relationship to materiality-is narrative seen as media agnostic, and not affected by digital procedural media, or is it understood as considerably affected, which would mean that Interactive narrative has specific qualities, and is effectively a separate entity.

The impact of the player/interactor on the experience and their agency with regards to narrative is another important and frequently discussed aspect (e.g., (Wardrip-Fruin et al. 2009; Harrell and Zhu 2009; Knoller 2010; Mason 2013). I will use the term "player agency" for this dimension. Here, perspectives range from "not different to that of a novel" (player equals reader/viewer) to "significant change" (player has agency over the course of experience).

Thus, media specificity and user agency are represented in the two axis of the mapping. Both of these dimensions will be scored on a scale from 0 (no impact) to 6 (considerable impact) in the mapping. Individual positions on the scales on both dimensions are represented in more detail in the following tables (Tables 1 and 2).

Table 1. Scale for media specificity.

\begin{tabular}{|c|c|c|c|c|c|c|c|}
\hline Score & 0 & 1 & 2 & 3 & 4 & 5 & 6 \\
\hline Desc. & $\begin{array}{l}\text { Narrative } \\
\text { is not } \\
\text { affected by } \\
\text { the digital } \\
\text { medium, it } \\
\text { is the same } \\
\text { entity as a } \\
\text { book or } \\
\text { film }\end{array}$ & $\begin{array}{l}\text { There is some } \\
\text { influence of } \\
\text { the digital } \\
\text { medium, yet } \\
\text { narrative is } \\
\text { properly } \\
\text { manifested in } \\
\text { non-digital } \\
\text { forms }\end{array}$ & $\begin{array}{l}\text { Some genres } \\
\text { of digital } \\
\text { narrative } \\
\text { exist; } \\
\text { however, } \\
\text { these are } \\
\text { digital } \\
\text { versions of } \\
\text { analog } \\
\text { manifestations }\end{array}$ & $\begin{array}{l}\text { Some } \\
\text { aspects are } \\
\text { specific to } \\
\text { the digital } \\
\text { medium, } \\
\text { but not } \\
\text { enough to } \\
\text { consider } \\
\text { them } \\
\text { different } \\
\text { entities }\end{array}$ & $\begin{array}{l}\text { There are } \\
\text { specific } \\
\text { digital } \\
\text { narrative } \\
\text { genres, yet } \\
\text { these are } \\
\text { enabled by } \\
\text { non-digital } \\
\text { forms }\end{array}$ & $\begin{array}{l}\text { There is a clear } \\
\text { influence of } \\
\text { the digital } \\
\text { medium on } \\
\text { narrative, yet } \\
\text { some form of } \\
\text { media } \\
\text { agnosticism is } \\
\text { still } \\
\text { maintained }\end{array}$ & $\begin{array}{l}\text { Narrative is } \\
\text { considerably } \\
\text { affected by the } \\
\text { digital } \\
\text { medium; it is } \\
\text { a different } \\
\text { entity, in } \\
\text { contrast to a } \\
\text { book or film }\end{array}$ \\
\hline
\end{tabular}

Table 2. Scale for user agency.

\begin{tabular}{|c|c|c|c|c|c|c|c|}
\hline Score & 0 & 1 & 2 & 3 & 4 & 5 & 6 \\
\hline
\end{tabular}


Locating Positions

Using these scales, in the following section I briefly analyze a foundational canon of 11 publications (Murray 1997; Aarseth 1997; Juul 1998; Juul 2001; Juul 2005; Eskelinen 2001; Aarseth 2001; Jenkins 2004; Pearce 2004; Salen and Zimmerman 2004; Ryan 2006) on the topic of interactive and video game narrative, and score them on media specificity and user agency (Table 3). These scores were then used to create a two-dimensional mapping (Figure 1) which is discussed in Section 4 . The selection criteria for the canon were high-impact (a google scholar citation count of at least 200 citations $^{2}$ ) and from the formation years (1997-2006) of video game studies and related areas concerned with interactive forms of narration. More recent publications on the topic (e.g., (Eskelinen 2012; Ensslin 2014; Mukherjee 2015)) have not yet reached this level of impact. ${ }^{3}$ In addition, the concentration on earlier publications is purposeful, in order to address the issue at its origin.

Table 3. Positions in the analyzed publications.

\begin{tabular}{|c|c|c|c|c|c|}
\hline Author & Publication & Year & \multicolumn{2}{|c|}{ Media Specificity } & Player Agency \\
\hline Murray, Janet & $\begin{array}{l}\text { Hamlet on the } \\
\text { Holodeck }\end{array}$ & 1997 & \multicolumn{2}{|l|}{6} & 6 \\
\hline Aarseth, Espen & Cybertext & 1997 & \multicolumn{2}{|l|}{2} & 6 \\
\hline Juul, Jesper & $\begin{array}{c}\text { A Clash Between } \\
\text { Game and } \\
\text { Narrative }\end{array}$ & 1999 & \multicolumn{2}{|l|}{0} & 6 \\
\hline Juul, Jesper & $\begin{array}{l}\text { Games telling } \\
\text { Stories? }\end{array}$ & 2001 & \multicolumn{2}{|l|}{1} & 6 \\
\hline Aarseth, Espen & $\begin{array}{c}\text { Game Studies, } \\
\text { Year One }\end{array}$ & 2001 & \multicolumn{2}{|l|}{1} & 6 \\
\hline Juul, Jesper & Half Real & 2005 & \multicolumn{2}{|l|}{1} & 6 \\
\hline $\begin{array}{l}\text { Eskelinen, } \\
\text { Markku }\end{array}$ & $\begin{array}{l}\text { The Gaming } \\
\text { Situation }\end{array}$ & 2001 & \multicolumn{2}{|l|}{0} & 6 \\
\hline \multirow{6}{*}{ Pearce, Celia } & \multirow{6}{*}{$\begin{array}{c}\text { A Game Theory } \\
\text { of Games }\end{array}$} & \multirow{6}{*}{2004} & Experiential & 6 & 6 \\
\hline & & & Performative & 3 & 0 \\
\hline & & & Augmentary & 3 & 1 \\
\hline & & & Descriptive & & text) \\
\hline & & & Metastory & 3 & 1 \\
\hline & & & Story System & 6 & 6 \\
\hline \multirow{4}{*}{ Jenkins, Henry } & \multirow{4}{*}{$\begin{array}{c}\text { Game Design as } \\
\text { Narrative } \\
\text { Architecture }\end{array}$} & \multirow{4}{*}{2004} & Evocative & 4 & 3 \\
\hline & & & Enacted & 4 & 5 \\
\hline & & & Embedded & 6 & 2 \\
\hline & & & Emergent & 6 & 6 \\
\hline \multirow{2}{*}{$\begin{array}{c}\text { Salen \& } \\
\text { Zimmerman }\end{array}$} & \multirow{2}{*}{ Rules of Play } & \multirow{2}{*}{2004} & Embedded & 6 & 5 \\
\hline & & & Emergent & 6 & 6 \\
\hline \multirow{4}{*}{$\begin{array}{l}\text { Marie-Laure } \\
\text { Ryan }\end{array}$} & \multirow{4}{*}{ Avatars of Story } & \multirow{4}{*}{2006} & external—exploratory & 3 & 4 \\
\hline & & & internal-exploratory & 3 & 2 \\
\hline & & & external-ontological & 3 & 6 \\
\hline & & & internal-ontological & 3 & 6 \\
\hline
\end{tabular}

2 Citation count on scholar.google.com, September 2018: (Murray 1997) > 5000; (Aarseth 1997) > 4000; (Juul 1998) > 300; (Juul 2001) > 600; (Aarseth 2001) > 700; (Eskelinen 2001) > 600; (Pearce 2004) > 200; (Jenkins 2004) > 1400; (Salen and Zimmerman 2004) > 6000; (Juul 2005) > 2000; (Ryan 2006) > 600 .

3 Citation count on scholar.google.com, September 2018: (Eskelinen 2012) < 100; (Ensslin 2014) < 70; (Mukherjee 2015$)<30$. 


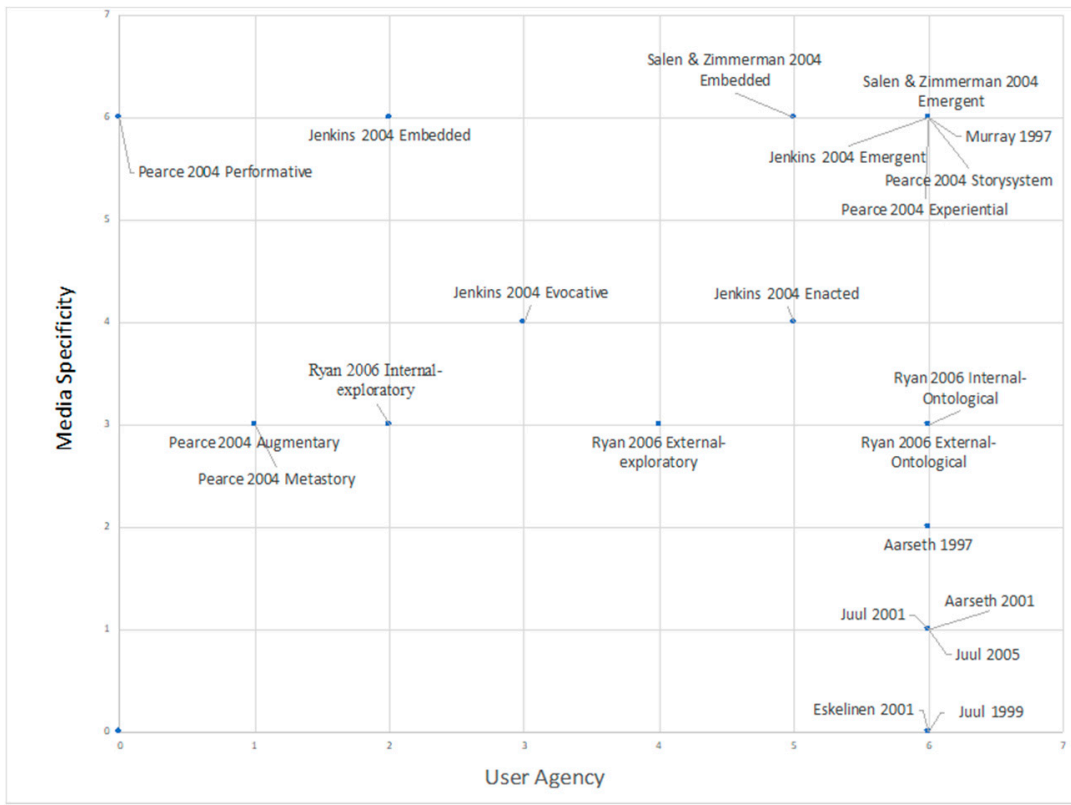

Figure 1. Spatial mapping of different ontological positions on interactive digital narrative.

Janet Murray's position in Hamlet on the Holodeck (Murray 1997) can be categorized as foregrounding the impact of the affordances of the digital medium (her categories of procedural, participatory, spatial, and encyclopedic) on narrative, as well as on the player's agency, which for her represents a fundamental aesthetic quality. Murray also associates an additional aspect of player agency with transformation, which is the dual quality of affecting change in the narrative, as well as being affected by the experience. This position will be ranked as high (6) on both dimensions.

Espen Aarseth in Cybertext (Aarseth 1997) introduced the notion of the "ergodic"-the non-trivial effort required by the audience to traverse an interactive narrative. In the present context, this translates to a high ranking on the user agency dimension (6). In respect to media specificity, Aarseth indeed champions novel narrative forms in mostly digital manifestations, for example adventure games. Yet, his insistence on a transmedial perspective on narrative (according to him, textual representations on paper can also qualify as cybertextual machines) results in a lower score on this dimension (2).

Similarly, Jesper Juul's initial rejection of narrative in games, when he says "the computer game is simply not a narrative medium" (Juul 1998), is in line with traditional perspectives in the humanities with regards to media specificity (narrative is not affected by the digital medium), as Juul understands narrative as immutable while emphasizing the difference to player agency in games. This perspective will be ranked low (0) on the media specificity dimension and high on player agency (6). Juul's later position from 2001 onward (Juul 2001) moves the position on the dimension of media specificity to 1, in line with Aarseth's later position (Aarseth 2001), while Eskelinen's pronouncement (Eskelinen 2001) of the incompatibility of narrative with games ranks lower (0). Juul's 2005 book Half-Real (Juul 2005) sees a role for narrative (in the guise of "fiction") in games, and thus might initially appear to open up towards a more media-specific understanding of narrative. However, Juul still preserves a dichotomic perspective, in which games represent an open structure and narrative a fixed, closed one. For him, the role of narrative in games is mostly ornamental to provide context, and thus is increasingly superfluous the more the player progresses. From the perspective of media specificity, the mapping of this positions thus remains at 1 , and player agency at 6 .

In 2004, Henry Jenkins published his essay "Game Design as Narrative Architecture" (Jenkins 2004), in which he argues for a media-specific perspective. He describes four specific modes for interactive digital narrative: "evocative", "enacted", "embedded", and "emergent". The evocative mode refers to narratives that reference prior stories in other media, e.g., a Harry Potter 
game. Enacted narratives allow the user to act out specific roles within an existing narrative universe, for example that of a Hobbit from Tolkien's Lord of the Rings. Embedded narratives convey information by means of spatially distributed narrative-infused encounters, as exemplified in the adventure game Myst (Cyan 1993). Finally, emergent narratives appear in rule-based game worlds that provide players with the tools to construct stories of their own (e.g., The Sims (Wright 2000)). With respect to media specificity and player agency, the different modes require individual assessment- the evocative and enacted modes cannot be ranked as fully media-specific, since Jenkins describes them as dependent on more traditional print literary or cinematic narratives. Consequently, they are ranked at 4 on this dimension. Player agency is medium (3) in the evocative mode, as it is restricted to the "satellite narratives" that cannot affect the main traditional narrative core, and higher in the enacted mode, but does not reach full agency for its dependence on the main narrative (5). For embedded narrative, media specificity ranks higher (6), yet user agency is limited to movement (2). Finally, emergent narrative ranks highly on both dimensions, as a media-specific form with extensive user agency $(6 / 6)$.

Celia Pearce, in her paper "A Game Theory of Game" (Pearce 2004), foregrounds a media specific perspective and argues for a different understanding of narrative-no longer as "storytelling", but in a "play-centric context". Pearce rejects literary and film theory and proposes a path towards a specific theory of games and narrative within games that casts narrative as a mostly experiential quality. Narrative games are successful, Pearce tells us, if they apply what is engaging and interesting about narrative and "use it to enhance the play experience". On this foundation, Pearce identifies six different modes of narrative in games. The first, "experiential", is the emergent narrative that stems from the conflict of the games as experienced by the player. According to Pearce, this mode exists in every game; it is media-specific (6), and the user has agency (6). The second mode, "performative", describes the same emergent narrative, but from the spectator position. This mode still ranks high on media specificity (6), but the spectator has no agency on their own (0). "Augmentary" is Pearce's term for supplemental "layers of information, interpretation, backstory, and contextual frameworks" that enhance the experience. This mode can include media-specific elements, but could also use traditional fixed-linear narrative modes, and is thus scored at the midpoint (3) for media specificity, while user agency is low (1). "Descriptive" denotes the retelling of game experiences to third parties, either in person or through platforms such as Twitch. This narrative mode will not be represented in the mapping, as it constitutes a "second order narrative" that happens outside of the direct relationship between player/interactor and the work. "Metastory" is similar to "augmentary", and is ranked in the same way (3/1), but instead describes a fully developed narrative framework. Finally, a "story system" allows the player to build her own narrative content from generic parts. This mode is similar to Jenkins' understanding of emergent narrative (6/6).

Similar to Pearce, Salen and Zimmerman in Rules of Play (Salen and Zimmerman 2004) see narrative mostly as an experiential quality, but focus on the designer's task in creating said experience. They describe two possible narratives modes: embedded and emergent. Their understanding of emergent narrative aligns with both Jenkins' and Pearce', and thus is ranked the same (6/6), yet their concept of embedded is broader than Jenkins'. For Salen and Zimmerman, an embedded narrative can be experienced through all kinds of interactions (not just spatial as with Jenkin's), therefore user agency is ranked high (5); however, this narrative mode misses the highest mark for the lack of control over the global narrative. Media specificity is high in this case too (6).

Marie-Laure Ryan, in her 2006 book Avatars of Story (Ryan 2006), approaches the question of interactive digital narrative from a narratological perspective. While she clearly acknowledges some of the changes brought about by the digital medium, and identifies some resulting opportunities and particular structures, she ultimately considers interactivity to be in conflict with narrative: "[ $\ldots$ ] interactivity is not a feature that facilitates the construction of narrative meaning". Therefore, on the media specificity dimension, her position is ranked at the midpoint (3). When it comes to player agency, Ryan's position requires a closer examination, as she offers a categorization of different 
types of interactivity along two different trajectories, internal-external and exploratory-ontological, which result in four different modes:

1. External-exploratory: the interactor makes choices in a game of discovery; e.g., text-based hypertext fiction,

2. Internal-exploratory: the interactor as a visitor with no ability to change; e.g., 360 video,

3. External-ontological: the interactor is a god; e.g., The Sims,

4. Internal-ontological: Interactor is a character in the virtual world, determining the fate of the avatar and the virtual world; e.g., Façade (Mateas and Stern 2005).

For the mapping, these modes equate to different levels of player agency. External-exploratory is at 4 because the interactor has control over choices, internal-exploratory is at 2 with limited agency (only in movement), and finally external-ontological and internal-ontological are at 6 , as the interactor has considerable impact on the narrative in both modes.

\section{Discussion}

Narrative under interactive conditions in the digital medium is a phenomenon that is not going to go away, instead, it will proliferate in different forms, from video games and interactive documentaries to installation pieces, not to mention journalistic interactives and AR/VR/MR (augmented reality/virtual reality/mixed reality) works. Interactive digital narrative thus represents a rich field for artistic experiments, journalistic information transfer, education, and entertainment, as well as related research. Yet so far, vague vocabulary with multiple contradictory meanings has existed, acting an impediment for both practice and research. The mapping presented in this paper addresses that challenge by identifying and positioning different perspectives on narrative. The result is an argumentative space that allows for productive critical comparisons of different positions. As a first effort of this kind, some of the values assigned might be subject to later revision. The mapping moves beyond binary perspectives and thus enables a novel perspective on the narratology versus ludology debate, no longer as a battle over the "correct" perspective, but as an encounter of different definitions of narrative within the same space.

Specifically, the mapping provides a number of insights. Two clusters exist around the maximum value of both dimensions ( 6 and 6 ), as well as around a point that is low on media specificity and high on user agency ( 0 and 6 , respectively). These two clusters represent the opposing positions in the narratology versus ludology debate. What we can learn from identifying these clusters is that the actual disagreement in the debate is about media specificity, not on user agency, since the majority of positions are closely aligned when it comes to the dimension of player agency. The takeaway here is that the debate should properly be regarded as being concerned with the aspect of media specificity of interactive narrative. This also means that "narratology versus ludology" description is a mislabeling. Consequently, future work can now concentrate on investigating these positions towards media specificity, in order to move the discussion forward.

Another aspect worth pointing out is that Aarseth's position from 2001 onward allows for less media specificity than his earlier perspective in Cybertext, which means his position has moved further away from the media-specific cluster around Murray's position, while Juul's trajectory is in the opposite direction. For future work, it would be interesting to investigate if (a) these movements continue and (b) how they are motivated by the two scholars.

We can also see that Jenkins' perspective encapsulates several different positions, making him less clearly placed amongst the proponents of specific interactive digital narrative forms clustered around Murray's position. Jenkins is thus not as good a representative of that position as Aarseth especially has portrayed him (e.g., in (Aarseth 2012)). Furthermore, engaging Jenkins' perspective properly would mean engaging either all or a specific one of these positions. The same insight holds true for Pearce' several positions, as well as Ryan's analytical framework along the dimensions of 
internal/external and exploratory/ontological. What these three scholars describe is not a single position, but rather a space within the mapping.

A further takeaway from the mapping is that the discrepancy in the ontological status of vocabulary pertains even to qualifications like "embedded narrative". This is clearly visible in the differing positions of Jenkins' use of the term to describe "environmental storytelling", in contrast to Salen and Zimmerman's meaning of "any kind of predetermined narrative structure".

\section{Conclusions}

The mapping introduced in this article is an instrument for visualizing the ontological differences between different scholars" perspectives on "narrative", as expressed in the foundational canon of publications on interactive forms of narrative. The resulting space is testimony to the diversity of opinions in this matter. More importantly, this representation provides a means to compare different positions by proximity and distance, as well as alignment versus the two dimensions. In this way, the representation provides a basis for an improved discourse on interactive forms of narration, overcoming simplistic binary oppositions used earlier, e.g., in the so-called "narratology versus ludology" debate. The insights presented in the discussion section show the potential of this approach.

In future work, the instrument could be extended in various ways-for instance, with additional authors' positions, a further dimension to create a three-dimensional mapping, or through comparisons with mappings featuring different dimensions. In addition, it would be interesting to map artifacts in this way, assessing where particular works could be located in this space.

Funding: This research received no external funding.

Conflicts of Interest: The author declares no conflict of interest.

\section{References}

Aarseth, Espen J. 1997. Cybertext. Baltimore: JHU Press.

Aarseth, Espen J. 2001. Computer Game Studies, Year One. Game Studies 1: 1-15.

Aarseth, Espen J. 2004. Genre Trouble. In First Person: New Media as Story, Performance, and Game. Edited by Noah Wardrip-Fruin and Pat Harrigan. Cambridge: MIT Press, Available online: www.electronicbookreview. $\mathrm{com} /$ thread/firstperson/vigilant (accessed on 6 July 2018).

Aarseth, Espen J. 2012. A Narrative Theory of Games. In Paper presented at FDG'12 Proceedings of the International Conference on the Foundations of Digital Games, Raleigh, NC, USA, May 29-June 1; pp. 1-5, ISBN 978-1-4503-1333-9.

AcademySoft. 1984. Tetris. Lyon: Infogrames Entertainment.

Bernstein, Mark, Michael Joyce, and David Levine. 1992. Contours of Constructive Hypertexts. In Paper presented at ECHT'92 Proceedings of the ACM Conference on Hypertext, Milan, Italy, November 30-December 4; New York: ACM, pp. 161-70. [CrossRef]

Bogost, Ian. 2017. Video Games Are Better without Stories. Theatlantic.com. April 24. Available online: https://www.theatlantic.com/technology/archive/2017/04/video-games-stories / 524148 /?utm_source=atlfb (accessed on 6 July 2018).

Bolter, Jay David. 1991. Writing Space. Mahwah: Lawrence Erlbaum.

Bolter, Jay David, and Michael Joyce. 1987. Hypertext and Creative Writing. In Paper presented at HYPERTEXT'87 Proceedings of the ACM Conference on Hypertext, Chapel Hill, NC, USA, November 13-15; New York: ACM, pp. 41-50. [CrossRef]

Buckles, Mary Ann. 1985. Interactive Fiction: The Computer Storygame 'Adventure'. Ph.D. thesis, University of California, San Diego, CA, USA.

Caillois, Roger. 1961. Man, Play, and Games. New York: Free Press of Glencoe.

Calleja, Gordon. 2009. Experiential Narrative in Game Environments. Paper presented at Digra 2015 Conference, Beijing, China, July 11-12; Available online: http:/ / www.digra.org/wp-content/uploads/digital-library/ 09287.07241.pdf (accessed on 6 July 2018). 
Calleja, Gordon. 2013. Narrative Involvement in Digital Games. Paper presented at Foundations of Digital Games 2013, Crete, Greece, May 14-17.

Calleja, Gordon. 2015. Game Narrative: An Alternate Genealogy. In Digital Interfaces in Situation of Mobility. New York: Springer Press.

Cyan. 1993. Myst. Eugene: Broderbund.

Ensslin, Astrid. 2014. Literary Gaming. Cambridge: MIT Press, pp. 1-217.

Eskelinen, Markku. 2001. The Gaming Situation. Game Studies 1. Available online: http:/ /www.gamestudies.org/ 0101/eskelinen/ (accessed on 6 July 2018).

Eskelinen, Markku. 2012. Cybertext Poetics. New York: Bloomsbury Publishing USA.

Fernández-Vara, Clara. 2014. Introduction to Game Analysis. Abingdon: Routledge.

Frasca, Gonzalo. 2003. Ludologists Love Stories, Too: Notes from a Debate That Never Took Place. Paper presented at Digital Games Research Conference 2003, Utrecht, The Netherlands, November 4-6.

Harrell, D. Fox, and Jichen Zhu. 2009. Agency Play: Dimensions of Agency for Interactive Narrative Design. Paper presented at 2nd AAAI Spring Symposium on Intelligent Narrative Technologies, Stanford, CA, USA, March 23-25.

Hayles, N. Katherine. 2002. Writing Machines. Cambridge: MIT Press.

Huizinga, Johan. 1938. Homo Ludens: A Study of the Play Element in Culture. Boston: The Bacon Press.

Jenkins, Henry. 2004. Game Design as Narrative Architecture. In First Person: New Media as Story, Performance, and Game. Edited by Noah Wardrip-Fruin and Pat Harrigan. Cambridge: MIT Press, Available online: http:/ / www.electronicbookreview.com/thread/firstperson/lazzi-fair (accessed on 6 July 2018).

Joyce, Michael. 1995. Of Two Minds. Ann Arbor: University of Michigan Press, Available online: http://press. umich.edu/script/press/10599 (accessed on 6 July 2018).

Juul, Jesper. 1998. A Clash between Game and Narrative. Paper presented at the Digital Arts and Culture Conference, Bergen, Norway, November 26-28.

Juul, Jesper. 2001. Games Telling Stories. Game Studies 1: 45.

Juul, Jesper. 2005. Half-Real. Cambridge: MIT Press.

Kapell, Matthew Wilhelm. 2015. The Play versus Story Divide in Game Studies. McFarland: Jefferson.

Knoller, Noam. 2010. Agency and the Art of Interactive Digital Storytelling. Berlin/Heidelberg: Springer, pp. 1-4.

Koenitz, Hartmut. 2016. Interactive Storytelling Paradigms and Representations: A Humanities-Based Perspective. In Handbook of Digital Games and Entertainment Technologies. Singapore: Springer, pp. 1-15.

Koenitz, Hartmut. 2018. Narrative in Video Games. In Encyclopedia of Computer Graphics and Games. Cham: Springer, vol. 1, pp. 1-9. [CrossRef]

Landow, George P. 1992. Hypertext. Baltimore: Johns Hopkins University Press.

Laurel, Brenda. 1986. Toward the Design of a Computer-Based Interactive Fantasy System. Ph.D. thesis, Ohio State University, Columbus, OH, USA.

Laurel, Brenda. 1991. Computers as Theatre. Boston: Addison-Wesley.

Mason, Stacey. 2013. On Games and Links: Extending the Vocabulary of Agency and Immersion in Interactive Narratives. In Interactive Storytelling, Proceedings 6th International Conference, ICIDS 2013, Istanbul, Turkey, 6-9 November 2013. Edited by Hartmut Koenitz, Gabriele Ferri, Mads Haar, Digdem Sezen, Tonguc Ibrahim Sezen and Güven Catak. Lecture Notes in Computer Science. Cham: Springer, vol. 8230, pp. 25-34. [CrossRef]

Mateas, Michael, and Andrew Stern. 2005. Structuring Content in the Façade Interactive Drama Architecture. In Paper presented at AIIDE'05 Proceedings of the First AAAI Conference on Artificial Intelligence and Interactive Digital Entertainment, Marina del Rey, CA, USA, June 1-3.

Montfort, Nick. 2005. Twisty Little Passages. Cambridge: MIT Press.

Mukherjee, Souvik. 2015. Video Games and Storytelling. Berlin/Heidelberg: Springer. [CrossRef]

Murray, Janet Horowitz. 1997. Hamlet on the Holodeck: The Future of Narrative in Cyberspace. New York: Free Press.

Murray, Janet. 1998. Hamlet on the Holodeck: The Future of Narrative in Cyberspace. Cambridge: MIT Press.

Murray, Janet H. 2004. From Game-Story to Cyberdrama. Electronicbookreview.com. January 5. Available online: http:/ / electronicbookreview.com/thread/firstperson/autodramatic (accessed on 6 July 2018).

Pearce, Celia. 2004. Towards a Game Theory of Game. In First Person: New Media as Story, Performance, and Game. Edited by Noah Wardrip-Fruin and Pat Harrigan. Cambridge: MIT Press, Available online: http:/ /www. electronicbookreview.com/thread/firstperson/tamagotchi (accessed on 6 July 2018).

Ryan, Marie-Laure. 2006. Avatars of Story. Minneapolis: University of Minnesota Press. 
Salen, Katie, and Eric Zimmerman. 2004. Rules of Play. Cambridge: MIT Press.

Simons, Jan. 2007. Narrative, Games, and Theory. Games Studies 7. Available online: http:/ /gamestudies.org/ 0701/articles/simons (accessed on 6 July 2018).

Stern, Andrew. 2008. Embracing the Combinatorial Explosion: A Brief Prescription for Interactive Story R\&D. In Interactive Storytelling, Proceedings First Joint International Conference on Interactive Digital Storytelling, ICIDS 2008 Erfurt, Germany, 26-29 November 2008. Lecture Notes in Computer Science. Berlin/Heidelberg: Springer, vol. 5334, pp. 1-5. [CrossRef]

Wardrip-Fruin, Noah, Michael Mateas, Steven Dow, and Serdar Sali. 2009. Agency Reconsidered. Paper presented at DiGRA Conference 2009, London, UK, August 30-September 4.

Wright, Will. 2000. The Sims [Video Game]. Redwood City: Electronic Arts.

(C) 2018 by the author. Licensee MDPI, Basel, Switzerland. This article is an open access article distributed under the terms and conditions of the Creative Commons Attribution (CC BY) license (http:// creativecommons.org/licenses/by/4.0/). 